\title{
Trust, Growth Mindset, and Student Commitment to Active Learning in a College Science Course
}

\author{
Andrew J. Cavanagh, ${ }^{+*}$ Xinnian Chen, ${ }^{\ddagger}$ Meghan Bathgate, ${ }^{\dagger}$ Jennifer Frederick, ${ }^{\dagger}$ \\ David I. Hanauer, $\$$ and Mark J. Graham ${ }^{\dagger}$ \\ ${ }^{\dagger}$ Center for Teaching and Learning, Yale University, New Haven, CT 06511; ;Department of \\ Physiology and Neurobiology, University of Connecticut, Storrs, CT 06269-2247; "Department \\ of English, Indiana University of Pennsylvania, Indiana, PA 15705-1094
}

\begin{abstract}
There is growing consensus regarding the effectiveness of active-learning pedagogies in college science courses. Less is known about ways that student-level factors contribute to positive outcomes in these contexts. The present study examines students' $(N=245)$ trust in the instructor-defined as perceptions of their instructor's understanding, acceptance, and care-and students' attitudes toward learning within an anatomy and physiology course featuring active learning. Analyses indicate that student trust of instructor and students' views of their own intelligence are both associated with student commitment to, and engagement in, active learning. Student-reported trust of the instructor corresponded to final grade, while students' views of their own intelligence did not. In an active-learning context in which students are more fully engaged in the learning process, student trust of the instructor was an important contributor to desired student outcomes.
\end{abstract}

\section{INTRODUCTION}

Research in undergraduate science, technology, engineering, and mathematics (STEM) education supports the use of active learning as a means of engaging students and improving learning outcomes across disciplines. Active learning involves a range of student-centered pedagogies that encourage engagement through activities such as peer collaboration, experimentation, writing, and problem solving (Handelsman et al., 2007). Previous findings suggest that active learning is effective because students are more engaged in course activities (Chasteen and Pollock, 2008; Wieman, 2014; Gross et al., 2015; Jensen et al., 2015). For example, a meta-analysis (Freeman et al., 2014) attributes a $10-12 \%$ gain in student performance when active learning is present to factors such as increased preclass preparation and more accurate completion of assignments. There are now calls for a more in-depth understanding of individual and classroom factors that contribute to student engagement, performance, and persistence in science courses featuring active learning (Dolan, 2015).

Many instructors are concerned about negative student perceptions of active learning - that is, that active learning is peripheral to the learning process or is too much work (Walker et al., 2008; Minhas et al., 2012; Brazeal et al., 2016; Nguyen et al., 2016). Elsewhere, we have developed a framework for understanding the nature of student responses to active-learning activities in STEM classrooms (Cavanagh et al., 2016). This framework highlights students' perceptions of active learning that maximize the impact of these pedagogies on student outcomes. To the extent that students are exposed to active learning, persuaded that active learning has educational value, and identify with active learning as personally beneficial to their learning, we expect them to commit to engaging in these activities (c.f. the EPIC model predicting student "buy-in" to active learning in Cavanagh et al., 2016). The
Mary Lee Ledbetter, Monitoring Editor Submitted June 21, 2017; Revised November 13, 2017; Accepted November 16, 2017

CBE Life Sci Educ March 1, 2018 17:ar10 DOI:10.1187/cbe.17-06-0107

*Address correspondence to: Andrew J. Cavanagh (andrew.cavanaghayale.edu). (c) 2018 A. J. Cavanagh et al. CBE-Life Sciences Education @ 2018 The American Society for Cell Biology. This article is distributed by The American Society for Cell Biology under license from the author(s). It is available to the public under an Attribution-Noncommercial-Share Alike 3.0 Unported Creative Commons License (http://creativecommons.org/licenses/ by-nc-sa/3.0).

"ASCB ${ }^{\oplus "}$ and "The American Society for Cell Biology ${ }^{\otimes}$ " are registered trademarks of The American Society for Cell Biology. 
exposure-persuasion-identification-commitment (EPIC) framework aims to describe inevitable variations in the level of student commitment to active learning within a course. This process is reflective of the way that faculty themselves adopt active learning and inclusive teaching pedagogies into their classrooms (Aragón et al., 2016).

Here, we explore factors that predict students' commitment to active learning. We seek to extend earlier findings that linked commitment, engagement, and performance in a course featuring active learning (Cavanagh et al., 2016). If students who are more committed to the principles of active learning are also more likely to be engaged learners, then it is important to understand predictors of both commitment and engagement. We consider the predictive role of two distinct theoretical frameworks from the education and psychology literatures. The first, trust, is an adaptation of the interpersonal relationship theory (Reis and Clark, 2013), which we define as students' belief that their instructor is understanding, accepting, and caring. The second, students' growth mindset, is a long-standing theoretical framework in the psychology and education research literature (Dweck and Leggett, 1988) that describes students' positive views about their own intelligence and ability to learn.

\section{Trust in an Active-Learning Context}

Active-learning environments are designed to maximize interaction between students and faculty (Freeman et al., 2007). A thorough understanding of the perceptions that students have of their instructor - from the first day of class through the end of the semester-is increasingly important when considering student-centered active-learning contexts. A growing literature on instructor-student interactions suggests that building personal connections with students improves a range of learning outcomes, including motivation (Komarraju et al., 2010), attitudes toward learning (Christophel, 1990), engagement (Umbach and Wawrzynski, 2005), and performance (Roorda et al., 2011). These connections are important in promoting positive learning outcomes for students from underrepresented groups (Lundberg and Schreiner, 2004) who withdraw from STEM disciplines at disproportionate rates (Wang and Degol, 2013).

While students' trust in their instructor can positively impact learning outcomes in a number of ways, this concept of trust has yet to be defined in a systematic way (Hagenauer and Volet, 2014). Existing studies tend to examine elements of studentteacher interactions that contribute to student motivation (Wentzel, 2016). Interestingly, research on student appraisals of faculty suggests that these judgments may be made in as little as 6 seconds and endure over the course of the semester (Ambady and Rosenthal, 1993; Tom et al., 2010). Thus, establishing trust early and often is likely to benefit instructors who are transforming their classroom through evidence-based teaching practices such as active learning, formative assessment, and inclusivity.

We adapt a close interpersonal relationship framework from the social psychology literature developed by Clark and Lemay (2010) as a lens to focus on the level of trust between students and a science instructor in an active-learning context. On the basis of Clark and Lemay (2010) and Reis et al. (2013), we define student trust as a perception that the instructor understands the challenges facing students as they progress through the course, accepts students for who they are, and cares about the educational welfare of students. To the extent that students trust their instructor - that is, believe that the instructor understands, accepts, and cares about their learning needs-we expect students to report positive learning experiences in that course. In active-learning contexts, one positive learning experience we find is that student commitment to student-centered pedagogies is related to positive self-regulated learning strategies and grades (Cavanagh et al., 2016). Students are likely to engage more if they trust that the course activities the instructor has chosen will benefit them (Reis et al., 2004). This requires the students to place a level of trust in the faculty member who is directing the course activities.

Gauging students' level of trust in their instructor is especially important when there is a "one-to-many" relationship (e.g., one instructor in a 200- to 300-seat classroom), because faculty in these contexts face a particularly steep challenge of building connections with individual students. This challenge is magnified when employing active learning, as faculty must not only adapt activities to fit the number of students in the classroom, but must also develop several response strategies when there are varying levels of student commitment to this way of learning (Exeter et al., 2010). Thus, student-instructor interactions and factors located within the classroom are important to consider in understanding student learning experiences in active-learning contexts.

\section{Growth Mindset and Active Learning}

Theories of intelligence describe students' approach to learning, capturing fundamental beliefs about one's ability to gain knowledge through experience (Dweck et al., 1995; Blackwell et al., 2007). Students who maintain growth mindsets tend to view intelligence as malleable and something that can be improved, while those with a fixed mindset believe intelligence is relatively unchanged by experience. Students with fixed beliefs are more likely to attribute knowledge and course performance to innate ability than those with growth-oriented views on intelligence, who tend to see classroom experiences as learning opportunities that may benefit their development (Dweck, 1986). Theories of intelligence have been related to motivation, goal pursuit, and effort in classroom settings (Blackwell et al., 2007; Komarraju and Nadler, 2013).

The empirical link between growth mindset and academic motivation is well established (Grant and Dweck, 2003; Dweck, 2008). What remains to be seen is whether these views impact other facets of student experiences in undergraduate STEM courses featuring active learning. In particular, does a growth mindset increase the likelihood that a student will commit to and/or engage in active learning? By design, an active-learning environment encourages students to be more open and committed to the learning process (Aragón et al., 2016). This line of inquiry proceeds from the simple premise that a student's belief about learning is likely to influence his or her learning (Dweck and Master, 2008). Research to date has provided support for a link between growth mindset and important learning outcomes, and in this study, we will explore the role of growth-oriented views toward learning in an active-learning classroom context.

\section{Summary}

Given the importance of trust and growth mindset to the goals and themes of active, student-centered classroom contexts, we hypothesize that each is positively associated with student 
commitment to active learning. We also explore the role of these factors in contributing to overall student engagement and course performance. Owing to the key role that the instructor plays in developing and implementing an active learning-based science course (Handelsman et al., 2007), we anticipate that students who report high levels of trust in their instructor are likely to respond more positively to, and be more engaged in, the active-learning context. Likewise, we expect a growth mindset to be positively associated with student commitment to active learning.

\section{METHODS}

\section{Participants and Procedure}

Participants ( $N=245 ; 64 \%$ female) were undergraduate students (54\% sophomores, 29\% juniors, 15\% seniors, and 2\% "other") who completed an online survey during the final 2 weeks of a Fall semester human anatomy and physiology course, a required two-semester course progression for science majors at the University of Connecticut. The materials were distributed to students using the Qualtrics survey software and completed online outside course meeting times. Participation was voluntary, and students were offered a small number of points toward the course grade for completing the survey. A separate study using the same participant data set established the relationship between student commitment to active learning (via an EPIC model), student engagement, and course grade (see Cavanagh et al., 2016). We use the term "student commitment" to represent the EPIC model and student buy-in process conceptualized in Cavanagh et al. (2016). This present research seeks to understand the relationship between prospective predictors of student commitment to active learning (i.e., trust, growth mindset) and important student outcomes, including engagement and course performance.

\section{Measures}

Student trust of the instructor was assessed using a derivation of Reis and Clark's (2013) relationship framework adapted by the authors for the college classroom setting. This was operationalized as a nine-item self-report measure in which students rated elements of their instructor's responsiveness, including understanding (three items; "My instructor gets me"), acceptance (three items; "My instructor accepts me for who I am"), and caring (three items; "My instructor truly cares about my educational welfare"). Participants indicated the extent to which they agreed with each of the statements using a scale ranging from 1 = "strongly disagree" to $5=$ "strongly agree." Scale reliability was acceptable $(\alpha=0.88)$. Two items ("It is difficult for my instructor to accept the nature of me" and "My instructor is not the sort of person who goes out of his or her way to show compassion to me") were reverse scored to ensure that higher scale scores indicated greater trust.

Participant attitudes toward learning were assessed using a validated three-item measure, with higher scores indicating a greater growth mindset ( $\alpha=0.89$; Dweck et al., 1995). Participants rated three items based on their level of agreement from 1 = "strongly disagree" to $6=$ "strongly agree." Scale items included "You have a certain amount of intelligence, and you can't really do much to change it"; "Your intelligence is something about you that you can't change very much"; and "You can learn new things, but you can't really change your basic intelligence." Each item was reverse scored so that higher scores indicated a more growth-oriented mindset.

Student commitment to active learning was assessed using a measure adapted by the current authors based on work by Aragón et al. (2016) to describe faculty adoption of evidence-based teaching practices. Students self-reported their commitment to 16 active-learning practices, and a commitment score was computed for each student based on responses to four subscales (Cavanagh et al., 2016), which included exposure to active learning ("I did this in this class"); persuasion as to the value of active learning ("I was convinced that this was good"); level of personal identification with each activity ("I liked doing this as a way to learn"); and commitment to engaging in these practices in the future ("I am committed to embracing this as a way of learning"). Items were coded on a dichotomous 0 (no) to 1 (yes) scale, with a higher sum score representing a higher level of commitment to active learning. A total sum score aggregating across all categories was computed for each student. Internal consistency was tested via the Kuder-Richardson reliability coefficient, used for scales with dichotomous response formats. Reliability was strong for the scale as a whole, (KR20 $=0.91)$, as well as for the exposure $(\mathrm{KR} 20=0.87)$, persuasion $($ KR20 $=0.92)$, identification $(K R 20=0.90)$, and commitment $(\mathrm{KR} 20=0.93)$ subscales.

The extent to which students were engaged in course activities was measured using five subscales of the Motivated Strategies for Learning Questionnaire (Pintrich et al., 1993; Duncan and McKeachie, 2005), which assesses self-regulated learning behavior on a 1-7 scale, with 7 indicating more engagement. Subscales included Elaboration (six items; "I try to apply ideas from course readings in other class activities such as lecture and discussion"; $\alpha=0.70$ ), Organization (four items; "When I study for this course, I go over my class notes and make an outline of important concepts"; $\alpha=0.66$ ), Time and Study Environment Management (eight items; "I make sure that I keep up with the weekly readings and assignments for this course"; $\alpha=0.74$ ), Metacognitive Self-Regulation (12 items; "When I study for this class, I set goals for myself in order to direct my activities in each study period"; $\alpha=0.72$ ), and Critical Thinking (five items; "Whenever I read or hear an assertion or conclusion in this class, I think about possible alternatives"; $\alpha=0.51$ ). Students rated 35 items across these five scales based on the extent to which each item represented their personal experience in the current course. Overall scale reliability was satisfactory $(\alpha=0.87)$.

The primary measure of course performance was students' final course grades, converted to a 100-point scale. Course grades were assigned by the same instructor in the same semester and incorporated in-class examinations (best three of four scores; $45 \%$ of final grade), laboratory component (25\% of final grade), and a final examination (30\% of final grade). An additional 5 points of credit (less than $1 \%$ of the final grade) were available to students for participation in active-learning activities such as clicker questions, weekly assignments, and concept mapping. Students received 1 extra credit point (less than $1 \%$ of final grade) for participation in this study.

\section{Analysis}

Our analyses progressed from scale-level descriptive statistics to examination of bivariate and multivariate relationships using correlation and regression, respectively. We first computed 
mean scale scores for each participant for trust, growth mindset, and self-regulated learning. Student commitment to active learning in this instructor's course was computed as a sum of "yes" responses on the EPIC items. Along with these descriptive statistics, we conducted a series of exploratory one-way analyses of variance (ANOVAs) to identify potential differences in mean scores of each variable among groups based on gender, race/ethnicity, and school year. We then computed bivariate correlational analyses to examine the strength and direction of the relationship between each pair of variables in the study.

To understand and clarify the relationships among all variables (trust, growth mindset, student commitment, engagement, and final grade), regression analyses were conducted in a series of increasingly complex cycles. Initial analyses explored bivariate relations in order to see potential predictive relationships, which were then used to underpin and direct the design of multiple regression analyses. These multiple regressions were designed to clarify the degree to which trust and mindset contribute to specific student outcomes.

We first conducted bivariate regressions between trust as an independent variable predicting each of the three outcomes of interest (i.e., trust predicting commitment, trust predicting engagement, and trust predicting final grade), then the relationship between growth mindset and each outcome. These bivariate regressions allowed us to explore the amount of variance in each outcome that was accounted for when considering each predictor (trust, mindset) on its own. Building on these analyses, we next computed a series of multivariate regressions that included trust and growth mindset as predictors within the same model. Here, we sought to identify the combined variance in each outcome that was accounted for when considering both independent variables in relation to a single outcome. We conducted three separate multivariate regression analyses, including the following: trust and mindset predicting commitment; trust and mindset predicting engagement; and trust and mindset predicting final grade. We completed all analyses using the IBM Statistical Package for the Social Sciences, version 24.0.

\section{RESULTS}

\section{Preliminary Analyses}

The overall mean for student trust in the instructor was high (mean $=3.91$ out of $5, \mathrm{SD}=0.62$ ), and the majority of students reported holding a growth mindset (mean $=4.04$ out of $6, \mathrm{SD}=1.13$ ). Student commitment to active learning varied among students in this course (mean $=20.91$ out of 64 , SD $=$ 11.74), though each student reported being committed to at least one practice. Students also reported moderate engage- ment on the self-regulated learning scale (mean $=4.63$ out of $7, \mathrm{SD}=0.68)$.

We next explored differences in responses among groups of students using a series of one-way ANOVAs. ANOVA allowed us to explore differences in student responses among naturally occurring groups (e.g., sex, race/ethnicity, and year in school) of students enrolled in the course.

With respect to gender, no significant differences were observed between men and women students for trust, $F(1,240)$ $=1.06, p=0.35$; growth mindset, $F(1,239)=1.39, p=0.25$; and self-regulated learning, $F(1,239)=2.33, p=0.10$. Men did, however, report significantly higher overall levels of commitment to active learning, $F(1,239)=4.56, p=0.01$, than women students. Regarding each step of EPIC, while no significant difference was observed with respect to exposure, $F(1,242)=1.49, p=0.23$, or identification, $F(1,229)=2.65, p=0.07$, male students reported significantly more persuasion, $F(1,215)=6.21, p=0.002$, and commitment, $F(1,203)=5.48, p=0.005$, to active learning than women. Course grade was not found to vary significantly between male and female students, $F(1,242)=0.45, p=0.64$.

Finally, we examined mean differences related to year in school and race/ethnicity. Only final grade was found to vary significantly by race/ethnicity, with majority students (mean = 81.6, $\mathrm{SD}=10.9$ ) scoring higher than underrepresented minority students $($ mean $=76.5, S D=12.9) ; F(1,231)=6.79, p=0.01$. All other differences were nonsignificant.

Following these ANOVAs, we next examined bivariate relationships among all variables using zero-order correlations. Table 1 displays correlational results for associations between each of the study variables, which provide a preliminary indication of the statistical significance, strength, and the direction (positive or negative) of associations among variables. There are three findings of interest. First, trust was found to be positively related to growth mindset, with students who reported high levels of trust in their instructor being likely to report growth mindsets. Trust was significantly and positively associated with student commitment to active learning and overall engagement in the course. Trust was also found to be significantly associated with final course grade, indicating that students who reported high levels of trust in their instructor tended to achieve higher course grades than those with lower trust levels.

Second, students reporting growth mindsets tended to also report high levels of both commitment to active learning and overall engagement. Interestingly, growth mindset was not found to be significantly associated with course grade. Each of the study outcomes (commitment to active learning, overall engagement, and course grade) was found to be positively and significantly related to the others.

TABLE 1. Zero-order correlations among study constructs

\begin{tabular}{|c|c|c|c|c|}
\hline & Trust & Growth mindset & Student commitment & Engagement \\
\hline 1. Trust & - & & & \\
\hline 2. Growth mindset & $0.20 * *$ & - & & \\
\hline 3. Student commitment & $0.40 * * *$ & $0.18 * *$ & - & \\
\hline 4. Engagement & $0.37 * *$ & $0.17^{* * *}$ & $0.40 * * *$ & - \\
\hline 5. Course grade & $0.25 * * *$ & 0.09 & $0.13^{*}$ & $0.28 * * *$ \\
\hline
\end{tabular}

${ }^{*} p<0.05$

$* * p<0.01$.

$* * * p<0.001$ 
Third, students who reported high levels of commitment to active learning also tended to report high levels of overall engagement and high course grades. These findings highlight the importance of student commitment to active learning, as it is statistically significantly related to two key outcomes for students, namely, overall engagement and course performance.

\section{Main Analyses}

On the basis of these favorable correlational results, we next conducted a series of bivariate regression analyses to test for direct associations between the two independent variables of interest (trust, growth mindset) and each of three student outcomes, including students' commitment to active learning, overall course engagement, and final grades. These regression analyses allowed us to test for main effects, or the extent to which scores on one measure predict variability in another measure. In addition, these regression analyses provided an indication of the amount of variance in each outcome that was accounted for by the independent variable, allowing for greater interpretation of the strength of the relationship between variables than can be explored in correlational analyses.

Before conducting these analyses, we tested for assumptions of regression to determine the suitability of the data for regression, including normality, linearity, homoscedasticity, and multicollinearity. Univariate normality was established by examining skewness and kurtosis for each variable. These values fell in an acceptable range for normality, between -1 and 1 , for each variable. We then visually examined scatter plots of residuals for signs of normality, linearity, and homoscedasticity and determined these residuals were sufficiently randomly distributed. Multicollinearity was ruled out through examination of correlational analyses. While most study variables were significantly related, the strength of these relationships were not strong enough (i.e., $>0.60$ ) to justify exclusion of any variable due to multicollinearity.

Consistent with findings from our correlational analyses, trust was found to be a statistically significant predictor of growth mindset $(\beta=0.20, p<0.01)$, as high levels of trust were associated with higher levels of growth mindset. Trust was found to significantly predict students' commitment to active learning $(\beta=0.40, p<0.001)$. Growth mindset was also found to be a statistically significant predictor of commitment $(\beta=$ $0.18, p<0.01$ ). Trust accounted for $16 \%$ of the overall variation in level of commitment to active learning, compared with growth mindset, which accounted for $4 \%$ of variation in com- mitment to active learning. Trust $(\beta=0.37, p<0.001)$ was also found to be a significant predictor of student engagement. Though growth mindset was found to be a statistically significant predictor of engagement, trust emerged as a stronger predictor of variation in engagement scores, as trust accounted for a higher percentage (13\%) of the variance in student engagement scores than growth mindset (3\%). Results for bivariate regression analyses are given in Appendix A in the Supplemental Material.

These bivariate regression analyses were helpful in elucidating the strength and direction of individual relationships among trust, growth mindset, and each of the three outcomes. Our next step was to test the combined explanatory power of the two predictor variables using multiple regression. These multivariate regressions provided us additional insight into the relationship between our two independent variables and three dependent measures by allowing us to examine trust and growth mindset as predictors within the same model. Three models were analyzed, one for each outcome, using both trust and growth mindset as independent variables.

Figure 1 presents findings for the three multiple regression analyses. When considering trust and growth mindset in the same regression, trust is a strong and positive predictor of each of the three outcomes, including commitment to active learning, $\beta=0.38, t(238)=6.29, p<0.001$; engagement, $\beta=0.35$, $t(239)=5.66, p<0.001$; and final course grade, $\beta=0.26$, $t(239)=4.05, p<0.001$. Growth mindset is a nonsignificant predictor of each outcome, indicating that trust is accounting for a significant amount of the variance in student commitment to active learning, engagement, and final course grade over and above the influence of growth mindset.

Together, trust and mindset account for $17 \%$ of the variance in student commitment to active learning, $R^{2}=0.17, F(2,238)=$ 24.67, $p<0.001 ; 14 \%$ of the variance in student engagement, $R^{2}=0.14, F(2,239)=19.83, p<0.001$; and $7 \%$ of the variance in final course grade, $R^{2}=0.07, F(2,239)=9.31, p<0.001$.

\section{DISCUSSION}

We explored two questions relating to active learning and student engagement in an undergraduate science course. The first explored a relatively new construct, students' trust in their instructor, as a predictor of student commitment to active learning, overall engagement, and course performance. The second tested a more established measure, growth mindset, as a predictor of these outcomes. Our results indicate that student-reported trust of the instructor and growth mindset were both significantly associated with commitment to active learning in the current course. It was level of trust, however, that emerged as the strongest and most consistent predictor of student commitment, engagement, and course performance. These findings reaffirm the key role of instructors in active-learning environments (Umbach and Wawrzynski, 2005). In this study, students' lack of trust was associated with decreased commitment to (and engagement in) active learning. Students who do not trust their instructor may
FIGURE 1. Multivariate regression analyses. All values represent standardized regression coefficients. ${ }^{* *}, p<0.01 ;{ }^{* * *}, p<0.001 ; n s$, nonsignificant. 
view active learning as a set of meaningless activities rather than an opportunity to learn. Moreover, trust may play a larger role in active-learning contexts in which students are asked to "do more" (e.g., discourse, reflect, and collaborate) than in lecture-based courses.

In exploring associations between student views on intelligence and learning experiences, we found a small but significant relationship between growth mindset and other study variables, including trust, commitment to active learning, and overall engagement. Surprisingly, growth mindset was not significantly associated with students' final grades; instead, trust, student commitment to active learning, and overall engagement each contributed more meaningfully to student performance in this active-learning context. These results suggest that, while global beliefs about the ability to learn remain important in predicting student engagement, the course experience itself (i.e., students developing trust in their instructor) was more important in predicting student success in this sample. This is encouraging, as faculty may find they have more capacity to impact student trust than to alter students' fundamental views about learning, which are typically more resistant to short-term change (Dweck, 2008).

Our results directly relate students' views of their instructor to their experiences with active learning. Students in this study who trusted their instructor were more committed to active learning. In this way, trust served as a gateway to engaging students. Students who trust their instructor likely benefit from an overall sense that help is available if needed and are therefore more willing to participate. Responsive practices that generate student trust are commonly seen in undergraduate classrooms, and many may be relatively easy to implement. For example: referring to students by their names; providing nonevaluative opportunities to allow students to work through problems; providing frequent feedback on student responses within individual and group settings; and encouraging a collaborative approach toward learning (Tanner, 2013). Our results demonstrate that, in building student trust, faculty simultaneously foster positive views of active learning and encourage student engagement in classroom activities.

\section{Limitations}

The present findings are exploratory in that they represent student experiences within a single course and in relation to one instructor who has demonstrated high competency with implementing active learning in a large classroom. The conclusions we have drawn are preliminary and serve as grounds for future studies that may provide more definitive concerning the factors that predict student commitment to active-learning classroom contexts. Our analyses tested influences on students' commitment to active learning via the EPIC framework (see Cavanagh et al., 2016). The correlational nature of these analyses leaves open the question of directionality in the relationships among trust, commitment to active learning, engagement, and academic performance. Additional work to test this model will be helpful in clarifying the link between trust and a variety of learning outcomes in active-learning contexts.

\section{Implications and Future Directions}

We found that trust was a stronger predictor of student outcomes (commitment, engagement, final grade) than growth mindset. This runs counterintuitive to literature that establishes growth mindset as a chronic measure of students' approach to learning that consistently predicts educational success in college populations (Grant and Dweck, 2003; Yeager and Dweck, 2012). These results highlight the importance of building student trust as a means for improving student learning outcomes in an active-learning context.

Faculty can build student trust by cultivating a sense that, while active learning may involve more work, "I have your best interests in mind," "I have your back," and "We're all in this together." It is critical to support these statements through responsive actions, including soliciting formative student feedback about course activities and teaching methods; using inclusive strategies such as universal design (Burgstahler, 2015); and being available before, during, and after class to answer student questions. Given that there were no differences found in student commitment based on race/ethnicity, these results are also hopeful in that they suggest building trust may benefit the learning experiences of students from all backgrounds.

Specific strategies used by the instructor in this course to promote student trust included the following: 1) being transparent about the purpose and goals of active learning; 2) highlighting the empirical evidence in support of these pedagogies and, specifically, how they would directly benefit the student; 3) ensuring consistent alignment between activities and assessments to promote the students' understanding that how they would be assessed related to what they did in class; and 4) encouraging a growth mindset toward learning. Given the relatively high level of trust present in this course, each of these actions may lead to student trust in the instructor by reinforcing that the instructor has introduced evidence-based pedagogies based on his/her level of care, acceptance, and understanding of student learning needs.

We found a statistically significant association between trust and course performance $(r=0.25, p<0.001$ ), with higher levels of trust positively associated with students' final course grades (see Figure 1). It is not yet known whether students' course performance is inextricably linked with the development of trust in the instructor. It may be that students who receive high marks are more likely to trust their instructor, thus creating a self-fulfilling prophecy. In contrast, course performance may undermine trust for students who are scoring below their expectations. In this study, trust was assessed before students knew their final grades. It is worth exploring the interaction between trust and formative feedback about course performance over the course of a semester to determine the causeand-effect relationship between these two constructs.

Because we show that student trust is particularly important within this active-learning context, further research will be useful in identifying whether this phenomenon holds in other courses featuring active learning. If so, it will be important to identify strategies that foster trust in these contexts. For example, examining students' trust in several instructors may help to determine whether there are specific instructor behaviors that best elicit student trust. This research will further be useful in determining 1) the extent to which student trust varies across instructors, and 2) whether instructor behaviors that foster student trust are associated with other positive outcomes, such as commitment to active learning and persistence in the sciences. In addition to identifying predictors of trust and/or growth 
mindset that may predict student outcomes in active-learning environments, careful analysis of classroom dynamics through observation may bring to the surface additional determinants of students' commitment to active learning, engagement, and performance in these environments.

There are additional questions related to trust in an active-learning setting that are worth exploring, including how best to build and maintain student trust over the course of a semester, the impact of trust on different types of engagement (e.g., cognitive, behavioral, affective; Wiggins et al., 2017), and factors that may predict the likelihood of trust between students and instructors. Additional research will also be helpful in determining whether negative views of active learning (Prince, 2004; Nguyen et al., 2017) may be attributed to the activities themselves, the instructor, or both.

\section{CONCLUSIONS}

Despite a strong empirical link between active learning and student engagement, less is known about factors leading to engagement in these contexts. This study examined two potential predictors of student commitment to engagement in an active-learning classroom: students' trust in their instructor and students' growth mindsets. Results revealed a consistent and strong relationship among trust, commitment to active learning, engagement, and final grade. These findings highlight the importance of student-instructor interactions in contributing to student commitment to and engagement in active-learning classroom contexts. Results indicate the importance of trust in active-learning environments and establish a need to further explore student-instructor interactions in active-learning contexts that encourage student engagement.

\section{ACKNOWLEDGMENTS}

Research that contributed in part to this paper was made possible through a National Science Foundation Transforming Undergraduate Research in the Sciences (TUES) grant (NSF\#1323258). Additional support for the Summer Institutes is provided by the Howard Hughes Medical Institute and the Helmsley Charitable Trust. We thank the Summer Institute leaders, facilitators, and participants for their responses and dedication. We thank our collaborators on this grant, including Brian Couch, Mary Durham, Monica Hargraves, Claire Hebbard, Jennifer Knight, Scott Strobel, and William Trochim.

\section{REFERENCES}

Ambady, N., \& Rosenthal, R. (1993). Half a minute: Predicting teacher evaluations from thin slices of nonverbal behavior and physical attractiveness. Journal of Personality and Social Psychology, 64, 431-441.

Aragón, O. R., Dovidio, J. F., \& Graham, M. J. (2016). Colorblind and multicultural ideologies are associated with faculty adoption of inclusive teaching practices. Journal of Diversity in Higher Education, 10(3), doi: 10.1037/ dhe0000026

Blackwell, L. S., Trzesniewski, K. H., \& Dweck, C. S. (2007). Implicit theories of intelligence predict achievement across an adolescent transition: A longitudinal study and an intervention. Child Development, 78(1), 246-263.

Brazeal, K. R., Brown, T. L., \& Couch, B. A. (2016). Characterizing student perceptions and buy-in toward common formative assessment techniques. CBE-Life Sciences Education, 15, ar73.

Burgstahler, S. E. (2015). Universal design in higher education: From principles to practice. Cambridge, MA: Harvard Education Press.
Cavanagh, A. J., Aragón, O. R., Chen, X., Couch, B., Durham, M., Bobrownicki, A., ... Graham, M. J. (2016). Student buy-in to active learning in a college science course. CBE-Life Sciences Education, 15(4), ar76.

Chasteen, S. V., \& Pollock, S. J. (2008). Transforming upper-division electricity and magnetism. In AIP conference proceedings (Vol. 1064, No. 1, pp. 91-94)

Christophel, D. (1990). The relationship among teacher immediacy behaviors, student motivation, and learning. Communication Education, 39(4), $323-340$.

Clark, M. S., \& Lemay, E. P. (2010). Close relationships. Handbook of social psychology (pp. 898-940). Hoboken, NJ: Wiley.

Dolan, E. L. (2015). Biology education research 2.0. CBE-Life Sciences Education, 14, ed1

Duncan, T. G., \& McKeachie, W. J. (2005). The making of the Motivated Strategies for Learning Questionnaire. Educational Psychology, 40, 117-128.

Dweck, C. (2008). Mindsets and math/science achievement (Prepared for the Carnegie Corporation of New York-Institute for Advanced Study Commission on Mathematics and Science Education). New York: Carnegie Corporation of New York. Retrieved from www.growthmindsetmaths .com/uploads/2/3/7/7/23776169/mindset_and_math_science_ achievement_-_nov_2013.pdf.

Dweck, C. S. (1986). Motivational processes affecting learning. American Psychologist, 41(10), 1040.

Dweck, C. S., Chiu, C. Y., \& Hong, Y. Y. (1995). Implicit theories and their role in judgments and reactions: A word from two perspectives. Psychological Inquiry, 6(4), 267-285

Dweck, C. S., \& Leggett, E. L. (1988). A social-cognitive approach to motivation and personality. Psychological Review, 95(2), 256.

Dweck, C. S., \& Master, A. (2008). Self-theories motivate self-regulated learning. In Schunk, D. H., \& Zimmerman, B. J. (Eds.), Motivation and self-regulated learning: Theory, research, and applications (pp. 31-51). New York: Taylor \& Francis

Exeter, D. J., Ameratunga, S., Ratima, M., Morton, S., Dickson, M., Hsu, D., \& Jackson, R. (2010). Student engagement in very large classes: The teachers' perspective. Studies in Higher Education, 35(7), 761-775

Freeman, S., Eddy, S. L., McDonough, M., Smith, M. K., Okoroafor, N., Jordt, H., ... Wenderoth, M. P. (2014). Active learning increases student performance in science, engineering, and mathematics. Proceedings of the National Academy of Sciences USA, 111, 8410-8415.

Freeman, S., O'Connor, E., Parks, J. W., Cunningham, M., Hurley, D., Haak, D., \& Wenderoth, M.P. (2007). Prescribed active learning increases performance in introductory biology. CBE-Life Sciences Education, 6, 132-139.

Grant, H., \& Dweck, C. S. (2003). Clarifying achievement goals and their impact. Journal of Personality and Social Psychology, 85(3), 541.

Gross, D., Pietri, E. S., Anderson, G., Moyano-Camihort, K., \& Graham, M.J. (2015). Increased preclass preparation underlies student outcome improvement in the flipped classroom. CBE-Life Sciences Education, 14, ar36.

Hagenauer, G., \& Volet, S. E. (2014). Teacher-student relationship at university: An important yet under-researched field. Oxford Review of Education, 40(3), 370-388.

Handelsman, J., Miller, S., \& Pfund, C. (2007). Scientific teaching. New York: Macmillan.

Jensen, J. L., Kummer, T. A., \& Godoy, P. D. D. M. (2015). Improvements from a flipped classroom may simply be the fruits of active learning. CBE-Life Sciences Education, 14(1), ar5.

Komarraju, M., Musulkin, S., \& Bhattacharya, G. (2010). Role of student-faculty interactions in developing college students' academic self-concept, motivation, and achievement. Journal of College Student Development, 51(3), 332-342.

Komarraju, M., \& Nadler, D. (2013). Self-efficacy and academic achievement: Why do implicit beliefs, goals, and effort regulation matter? Learning and Individual Differences, 25, 67-72.

Lundberg, C. A., \& Schreiner, L. A. (2004). Quality and frequency of faculty-student interaction as predictors of learning: An analysis of student race/ethnicity. Journal of College Student Development, 45(5), 549-565.

Minhas, P. S., Ghosh, A., \& Swanzy, L. (2012). The effects of passive and active learning on student preference and performance in an undergraduate basic science course. Anatomical Sciences Education, 5(4), 200-207. 


\section{A. J. Cavanagh et al.}

Nguyen, K., Husman, J., Borrego, M., Shekhar, P., Prince, M., Demonbrun, M., ... Waters, C. (2017). Students' expectations, types of instruction, and instructor strategies predicting student response to active learning. International Journal of Engineering Education, 33(1), 2-18.

Nguyen, K. A., Borrego, M., Finelli, C. J., Shekhar, P., DeMonbron, M., Hendersen, C., ... Waters, C. (2016). Measuring Student Response to Instructional Practices (StRIP) in Traditional and Active Classrooms, 2016 ASEE Annual Conference and Exposition, New Orleans, LA.

Pintrich, P. R., Smith, D. A., García, T., \& McKeachie, W. J. (1993). Reliability and predictive validity of the Motivated Strategies for Learning Questionnaire (MSLQ). Educational and Psychological Measurement, 53, 801-813.

Prince, M. (2004). Does active learning work? A review of the research. Journal of Engineering Education, 93(3), 223-231.

Reis, H. T., Aron, A., Clark, M. S., \& Finkel, E. J. (2013). Ellen Berscheid, Elaine Hatfield, and the emergence of relationship science. Perspectives on Psychological Science, 8(5), 558-572.

Reis, H. T., \& Clark, M. S. (2013). Responsiveness. In Simpson, J. A., \& Campbell, L. (Eds.), The Oxford handbook of close relationships (pp. 400-423). New York: Oxford University Press.

Reis, H. T., Clark, M. S., \& Holmes, J. G. (2004). Perceived partner responsiveness as an organizing construct in the study of intimacy and closeness. Handbook of Closeness and Intimacy, 201-225.

Roorda, D. L., Koomen, H. M., Spilt, J. L., \& Oort, F. J. (2011). The influence of affective teacher-student relationships on students' school engagement and achievement: A meta-analytic approach. Review of Educational Research, 81(4), 493-529.
Tanner, K. D. (2013). Structure matters: Twenty-one teaching strategies to promote student engagement and cultivate classroom equity. CBE-Life Sciences Education, 12, 322-331.

Tom, G., Tong, S. T., \& Hesse, C. (2010). Thick slice and thin slice teaching evaluations. Social Psychology of Education, 13, 129-136.

Umbach, P. D., \& Wawrzynski, M. R. (2005). Faculty do matter: The role of college faculty in student learning and engagement. Research in Higher Education, 46(2), 153-184.

Walker, J. D., Cotner, S. H., Baepler, P. M., \& Decker, M. D. (2008). A delicate balance: Integrating active learning into a large lecture course. CBE-Life Sciences Education, 7(4), 361-367.

Wang, M. T., \& Degol, J. (2013). Motivational pathways to STEM career choices: Using expectancy-value perspective to understand individual and gender differences in STEM fields. Developmental Review, 33(4), 304-340.

Wentzel, K. R. (2016). Teacher-student relationships. In Wentzel, K. R., \& Miele, D. B. (Eds.), Handbook of motivation at school (pp. 211-230). New York: Routledge.

Wieman, C. E. (2014). Large-scale comparison of science teaching methods sends clear message. Proceedings of the National Academy of Sciences USA, 111(23), 8319-8320

Wiggins, B. L., Eddy, S. L., Wener-Fligner, L., Freisem, K., Grunspan, D. Z., Theobald, E. J., ... Crowe, A. J. (2017). ASPECT: A survey to assess student perspective of engagement in an active-learning classroom. CBE-Life Sciences Education, 16(2), ar32.

Yeager, D. S., \& Dweck, C. S. (2012). Mindsets that promote resilience: When students believe that personal characteristics can be developed. Educational Psychologist, 47(4), 302-314. 